\title{
Contabilidade Ambiental: um estudo exploratório sobre o co- nhecimento dos profissionais de contabilidade
}

\author{
Environmental Accounting: an exploratory study about the knowledge of the accounting pro- \\ fessionals
}

\section{Carolina Veloso Maciel}

Mestranda em Ciências Contábeis na Universidade Federal de Pernambuco

Endereço: Prof. Moraes Rego, S/N Departamento de Ciências Contábeis/CCSA, Cidade Universitária.

CEP:50670-901 - Recife/PE- Brasil

E-mail: carolina.velosomaciel@gmail.com

Telefone: (81) 2126-8369

\section{Umbelina Cravo Teixeira Lagioia}

Doutora em Administração na Universidade Federal de Pernambuco

Professora do Mestrado em Ciências Contábeis da Universidade Federal de Pernambuco

Endereço: Prof. Moraes Rego, S/N Departamento de Ciências Contábeis, sala E-16 / CCSA, Cidade Universitária.

CEP:50670-901 - Recife/PE- Brasil

E-mail: umbelina@ufpe.br

Telefone: (81) 2126-8369

\section{Jeronymo José Libonati}

Doutor em Controladoria/Contabilidade na Universidade de São Paulo

Professor do Mestrado em Ciências Contábeis da Universidade Federal de Pernambuco

Endereço: Prof. Moraes Rego, S/N Departamento de Ciências Contábeis/CCSA, Cidade Universitária.

CEP:50670-901 - Recife/PE- Brasil

E-mail: jeronymolibonati@yahoo.com.br

Telefone: (81) 2126-8369

\section{Raimundo Nonato Rodrigues}

Doutor em Controladoria/Contabilidade na Universidade de São Paulo

Professor do Mestrado em Ciências Contábeis da Universidade Federal de Pernambuco

Endereço: Prof. Moraes Rêgo, S/N Departamento de Ciências Contábeis, sala E-16 / CCSA, Cidade Universitária

CEP: 50670-901 - Recife/PE- Brasil

E-mail: rnrodrigues13@yahoo.com.br

Telefone: (81) 2126-8369

Artigo recebido em janeiro de 2009. Passou por uma avaliação double blind review em julho de 2009. Aceito em outubro de 2009 pela Editora Científica Sandra Rolim Ensslin. Artigo apresentado no 5 Congresso USP de Iniciação Científica, 2008, São Paulo, 2008. 


\title{
Resumo
}

Este estudo tem como objetivo evidenciar o nível de conhecimento dos profissionais de Contabilidade sobre as peculiaridades da Contabilidade Ambiental. Para tanto, realizou-se uma pesquisa de campo, por meio da aplicação de 78 questionários estruturados, com os alunos de Pós-Graduação (lato sensu) do Departamento de Ciências Contábeis da UFPE, nos campi Recife e Caruaru, com perguntas sobre assuntos referentes à Contabilidade Ambiental. Após a tabulação dos dados coletados com a pesquisa, foi realizada uma análise estatística descritiva, e ficou constatado o baixo grau de conhecimento dos contadores sobre a Contabilidade Ambiental, a ausência de disciplinas ou correlatas e a falta de interesse dos profissionais em ler materiais sobre a disciplina ou participar de eventos relacionados à área.

Palavras-chave: Contabilidade Ambiental, Sustentabilidade, Conhecimento Contábil.

\begin{abstract}
This study aims to reveal the level of knowledge that accounting professionals have about the specificities of Environmental Accounting. To accomplish this goal, a field research was conducted by administering a structured questionnaire to 78 graduate students from the Accounting Department at UFPE (Universidade Federal de Pernambuco) in the Recife and Caruaru campi. The questionnaire included questions related to Environmental Accounting issues. The data were tabulated and underwent descriptive statistical analysis, which revealed the low level of knowledge that accountants have about Environmental Accounting, a lack of disciplines in this area, and the little interest that these professionals have in reading texts or attending events in the area.
\end{abstract}

Key words: Environmental Accounting, Sustainability, Accounting Knowledge.

\section{Introdução}

Com os avanços tecnológicos e o desenvolvimento da população, as atividades humanas originaram impactos negativos ao meio ambiente que, durante séculos, foi visto como fonte inesgotável de recursos naturais tendo como objetivo suprir as necessidades do homem. As preocupações relativas ao meio ambiente que vêm sendo discutidas no mundo inteiro decorrem da evidência de que atividades humanas, de modo geral, como empresas, governos e indivíduos, não se preocupam com a preservação ambiental, e essa preocupação é crucial para a existência das futuras gerações.

Atualmente, a visão ambientalista da sustentabilidade, não por acaso, também emergiu, com o passar dos anos, da consciência sobre as novas fontes de geração de riquezas - todas elas relacionadas com o capital social e o capital humano de um povo. Informação e conhecimento são condições básicas para o ciclo de prosperidade que o século vigente prenuncia. Nesse sentido, o desenvolvimento sustentável nada mais é do que a política de defesa e acumulação desse capital que constitui a nova riqueza das nações (ANDRADE, 2003).

Um dos elementos para que ocorra a promoção do desenvolvimento susten- 
tável é o combate à poluição, e, para isso, várias ciências e áreas do conhecimento estão empenhadas em contribuir com essa causa, de acordo com seu campo de atuação. A participação da Contabilidade ocorre na medida em que ela registra os eventos de natureza ambiental que causam impactos significativos na situação econômico-financeira das empresas (RIBEIRO, 2005).

A Contabilidade é uma ciência social e utiliza elementos de vários ramos do conhecimento para a construção do seu arcabouço teórico. Ela possui uma inter-relação com a Administração, com a Economia, com a Estatística e com várias outras disciplinas correlatas. Por haver essa inter-relação de informações, a Contabilidade torna-se de ampla aplicabilidade, e a atuação do profissional, da mesma forma, é bastante extensa (MARION, 2005).

O campo de atuação da Contabilidade, ou seja, seu objeto é o patrimônio de qualquer entidade pelo acompanhamento da evolução qualitativa e quantitativa desse patrimônio. Dessa forma, a Contabilidade é, objetivamente, um sistema de informação e avaliação destinado a prover seus usuários com demonstrações e análises de natureza econômica, financeira, física, de produtividade, social e ambiental, com relação à entidade objeto de contabilização (IUDÍCIBUS, MARTINS e GELBCKE, 2003).

Nesse contexto, Queiroz (2000) afirma que, sendo a Contabilidade um excelente instrumento de identificação, registro, acumulação, análise e interpretação das operações empresariais, ela deve desencadear soluções para que as empresas, por meio do planejamento estratégico, venham a encontrar o melhor caminho a ser seguido em termos de implantação de políticas que visam ao desenvolvimento sustentável.

Assim, a Contabilidade apresenta função social relevante no que diz respeito às informações relativas aos impactos sociais e ambientais causados pelas entidades. É cada vez mais frequente a busca dos usuários por informações sócio-ambientais junto às empresas, exigindo destas uma responsabilidade não só interna como também externa, ou seja, que afete a sociedade e o meio ambiente no qual está inserida (ALBUQUERQUE et al., 2007). Para tal, é mister que exista a inclusão dos profissionais de Contabilidade nesse processo de sustentabilidade para que atendam à demanda por informações ambientais, sendo necessário que tenham conhecimento sobre as peculiaridades da Contabilidade Ambiental.

Os profissionais das mais variadas áreas estão procurando se integrar para desenvolver ações que possibilitem atenuar as agressões praticadas pelos agentes degradantes do meio ambiente. Dentre as profissões que possuem um relevante poder de contribuição para esta causa, pode-se destacar a Contábil, pois, segundo Franco (1999, p. 64),

O profissional de Contabilidade não pode ficar indiferente a essa problemática do mundo moderno, porque sua atividade está 

muitas vezes, poluidoras, possuem um elevado poder para contribuir com ações para solucionar os problemas ecológicos.

A Contabilidade Ambiental surge com o objetivo de auferir os resultados das atividades das empresas relacionadas com o meio ambiente; portanto, não se trata de uma nova ciência, e sim, de novas informações que estão sendo demandadas por seus usuários (FERREIRA, 1998, 2003; RIBEIRO, 1998).

Costa, Libonati e Rodrigues (2004), em pesquisa realizada com contadores da Região Metropolitana do Recife sobre a Contabilidade Rural, perceberam o baixo grau de conhecimento dos profissionais a respeito das peculiaridades desse ramo da Contabilidade de grande importância. Por esse motivo, esta pesquisa investigou o grau de conhecimento dos contadores da Contabilidade Ambiental.

Nesse contexto, emerge o seguinte questionamento: Qual o nível de conhecimento dos profissionais de Contabilidade sobre as particularidades da Contabilidade Ambiental?

Dadas as mudanças conjunturais da sociedade com o aumento expressivo da industrialização e a crescente demanda de consumo e de produção acompanhada pelo aumento populacional, torna-se fundamental para as empresas, para o governo e para a sociedade ter o conhecimento do impacto causado pelas entidades no meio ambiente em que atuam. Nesse contexto, a Contabilidade emerge com o objetivo precípuo de prestar essas informações aos seus diversos usuários. Para a consecução dessa finalidade, a Contabilidade precisa se adaptar às mudanças da sociedade, assumindo novas características (ALBUQUERQUE et al.,2007).

A pesquisa torna-se relevante devido à preocupação global com a sustentabilidade ambiental, sobretudo no Brasil, que é um país com vasta disponibilidade de recursos naturais e com perspectivas de desenvolvimento econômico. Portanto, a Contabilidade emerge como uma ferramenta que tem relevância para os gestores na tomada de decisões com vistas a garantir a sustentabilidade em seus projetos empresariais.

Nesse contexto, o objetivo geral desta pesquisa consiste em identificar qual o grau de conhecimento dos contadores acerca das peculiaridades da Contabilidade Ambiental.

Para dar conta do objetivo geral, foram delineados os seguintes objetivos específicos: (i) descrever os conceitos da Contabilidade Ambiental; (ii) citar as principais peculiaridades da Contabilidade Ambiental; (iii) identificar o nível de compreensão dos contadores quanto à Contabilidade Ambiental; e, (iv) confrontar os resultados obtidos com os encontrados na literatura.

A pesquisa limitou-se aos contadores que fazem cursos de Pós-Graduação (lato sensu) oferecidos pelo Departamento de Ciências Contábeis da Universidade Federal de Pernambuco - UFPE, tanto no campus de Recife como no de 
Caruaru.

\section{Procedimento Metodológico}

\subsection{Natureza da Pesquisa}

A elaboração deste estudo é produto de uma pesquisa com caráter quantitativo e qualitativo. De acordo com Denzim e Lincoln (1994), a análise qualitativa corresponde a um conjunto de operações necessárias para a sistematização e para a formação coerente de um processo de coleta, armazenagem e recuperação de dados. Beuren (2004) explica que a pesquisa quantitativa utiliza instrumentos estatísticos para coletar e analisar esses dados. Para tanto, são expostos os resultados da pesquisa em tabelas e quadros. Martins e Theóphilo (2007) complementam afirmando que é descabido o entendimento de que possa haver pesquisa exclusivamente qualitativa ou quantitativa, visto que a investigação científica contempla ambas. Os procedimentos metodológicos utilizados na pesquisa apoiam-se nos fundamentos propostos por Malhotra (2001) e Copper e Schindler (2003). Dessa maneira, ela pode ser classificada como exploratória, tendo em vista que se busca descobrir ideias e dados para melhor compreensão do fenômeno em tela. $\mathrm{O}$ estudo exploratório pode ser definido como sendo uma das principais formas de construção do conhecimento em uma área nova ou pouco trabalhada, permitindo ao investigador aumentar sua experiência em torno de um determinado problema (TRIVIÑOS, 1987; GEORGE, 2002). Também alicerça o presente estudo uma pesquisa bibliográfica. Silva (2003) esclarece que essa pesquisa explica e discute um tema, ou problema, com base em referências teóricas já publicadas em livros, revistas, periódicos e artigos científicos.

\subsection{Instrumento da Pesquisa de Campo}

Com relação aos procedimentos empíricos a serem utilizados no trabalho, empregaram-se os mecanismos de levantamento ou pesquisa de campo que buscam as informações diretamente numa amostra da população estudada. Segundo Ruiz (1988, p. 50), "a pesquisa de campo consiste na observação dos fatos tal como ocorrem espontaneamente, na coleta de dados e no registro de variáveis presumivelmente relevantes para ulteriores análises".

Como instrumento desta pesquisa, adotou-se um questionário estruturado em que a coleta de dados foi feita de maneira transversal única, por meio da utilização do método de survey. O questionário apresenta 17 questões e está divido em duas partes: em primeiro lugar com o intuito de identificar o perfil do entrevistado, e, em segundo, averiguar seu conhecimento sobre Contabilidade Ambiental. 
A primeira parte fornece as seguintes informações sobre o respondente: Qual o seu curso de graduação; se foi realizado em faculdade pública ou privada; se já cursou alguma disciplina sobre Contabilidade Ambiental; a sua frequência em participação em eventos na área; se possuiu contato com alguma literatura especializada da área; e, por fim, o seu nível de conhecimento sobre Contabilidade Ambiental. Para essa última assertiva, foi utilizada uma escala Likert de cinco pontos, indo de Desconheço totalmente (ponto 1) até Conheço totalmente (ponto 5). A segunda parte do questionário apresenta questões que foram elaboradas com o intuito de verificar o conhecimento geral do entrevistado referente à Contabilidade Ambiental.

\subsection{Período da Aplicação do Questionário}

O período de aplicação do questionário ocorreu durante os meses julho e agosto de 2007 nos campi de Recife e de Caruaru do Centro de Ciências Sociais Aplicadas (CCSA) da Universidade Federal de Pernambuco (UFPE).

\subsection{Universo, População-Alvo e Amostra}

Foram escolhidos, como universo, os contadores do estado de Pernambuco; como População-Alvo, os alunos dos cursos de Pós-Graduação (lato sensu) oferecidos pelo Departamento de Ciências Contábeis do CCSA da UFPE; e, como amostra, os alunos formados em Ciências Contábeis, tendo em vista que alguns alunos dos referidos cursos são profissionais de outras áreas. Dessa forma, a amostragem caracteriza-se como não probabilística e intencional, pois a escolha da amostra não foi por acaso, tendo sido feita uma seleção dos itens que melhor reproduzem a População-Alvo investigada. Os contadores foram escolhidos por serem os profissionais visados no problema deste artigo.

Foram aplicados 78 questionários, dos quais 58 foram respondidos por contadores e 20 por profissionais graduados em outros cursos.

\subsection{Tratamento dos Dados Coletados}

Após a coleta dos dados, procedeu-se à análise e interpretação. Na análise, sumarizaram-se os dados para transformá-los em informações que esclarecessem o problema proposto. $\mathrm{O}$ tratamento dos dados consistiu na análise descritiva, pois eles foram analisados com o objetivo de se descobrirem as características do fenômeno estudado.

Os dados obtidos na presente pesquisa de campo foram selecionados e compilados no Statistics Package for Social Sciences 14.0 - SPSS. Os nomes 
das instituições, onde os entrevistados obtiveram a graduação, foram omitidos, pois não era o objetivo do trabalho pesquisar a grade curricular das instituições envolvidas.

\section{REFERENCIAL TEÓRICO}

\subsection{Contabilidade Ambiental}

A Contabilidade Ambiental passou a ter status de novo ramo da ciência contábil em fevereiro de 1998, com a finalização do "Relatório financeiro e contábil sobre o passivo e custos ambientais" pelo Grupo de Trabalho Intergovernamental das Nações Unidas de Especialistas em Padrão Internacionais de Contabilidade e Relatórios (TINOCO e KRAEMER, 2004).Tem como objetivo auferir os resultados das atividades das empresas relacionadas com o meio ambiente; portanto, não se trata de uma nova ciência, e sim, de informações que estão sendo demandadas por usuários da Contabilidade, devendo então serem evidenciadas contabilmente (FERREIRA, 1998, 2003; RIBEIRO, 1998).

A Contabilidade surge como um dos principais instrumentos de informação para a gestão das empresas e não pode deixar de desenvolver métodos capazes de incorporar às suas demonstrações dados específicos sobre o meio ambiente, relativos tanto à poluição quanto à despoluição, principalmente devido ao postulado da Continuidade que pressupõe a existência da entidade por prazo infinitivo, o que vai se adequar perfeitamente à entidade maior, o nosso Planeta (FERREIRA, 1995),

Segundo Ribeiro (2005, p. 44), o papel de contador no processo de sustentabilidade vai além e

como os demais cidadãos e profissionais (engenheiros, economistas, advogados, médicos e outros) têm a responsabilidade de contribuir para solucionar problemas ambientais, que podem ser de 3 maneiras: (1) determinação dos custos (considerando em especial para os custos sociais); (2) serviço de gerencia; e (3) da informação.

Cabe à Contabilidade Ambiental divulgar informações que vão desde os investimentos realizados com a aquisição de bens permanentes referentes à proteção de potenciais danos ecológicos ou em despesas que tenham por finalidade a correção de efeitos ambientais do exercício em curso, obrigações essas que foram contraídas em prol do meio ambiente, incluindo medidas físicas, quantitativas e qualitativas, voltadas à sua recuperação e preservação.

\subsection{Demonstrações Contábeis}


As demonstrações contábeis exigidas pela Lei n. 6.404/76 são ferramentas relevantes no processo de gestão e da tomada de decisões estratégicas para as entidades. Em se tratando da divulgação das demonstrações contábeis ambientais, que ainda não são exigidas por lei, e para atender às necessidades dos usuários da informação contábil, visando manter a credibilidade da empresa e sua consequente continuidade, torna-se necessário que o contador utilize novos métodos informativos, como o Balanço Social que tem como objetivo genérico suprir as necessidades de apresentação de informações de caráter social e ecológico (KROETZ, 2000).

De acordo com Albuquerque et al. (2007), as informações sobre a situação ambiental das empresas podem ser utilizadas para a ponderação de vários aspectos como: a) Encorajar operações para melhorar as práticas de fabricação, visando à redução de resíduos; b) Investir em pesquisa e tecnologia; c) Diversificar a produção; d) Mudar a rota dos negócios; e) Subsidiar programa de gerenciamento de riscos; f) Determinar os níveis adequados de reservas financeiras; g) Reformular a estratégia da companhia e das práticas gerenciais; h) Obter financiamentos.

Quando se discute a forma de divulgação da informação contábil de caráter social e ambiental, existem duas vertentes de pensamento: uma que propõe a implementação de um novo relatório separado das demonstrações contábeis, tratando apenas das questões ambientais; e uma segunda linha que sugere a inclusão destes dados nas atuais demonstrações, mantendo o padrão já utilizado, sendo utilizadas notas explicativas especificas. A segunda opção seria a mais indicada, pelo menos para o curto prazo, já que trata de aspectos inseridos no contexto operacional da empresa e, inclusive, para atender à necessidade imediata de a Contabilidade melhor informar seus usuários sobre o real valor patrimonial das empresas, sem maior perda de tempo em um processo de elaboração e implantação de um novo relatório (RIBEIRO apud FREY e PIRES JÚNIOR, 2001). O tópico seguinte apresenta o Balanço Social como instrumento de divulgação da responsabilidade social de uma organização.

\subsection{Balanço Social}

O Balanço Social consiste em um instrumento de evidenciação da responsabilidade social das entidades, ou seja, é a demonstração da interação da empresa com todos que a cercam ou que contribuem para sua existência, como o meio ambiente, a comunidade na qual a empresa está situada e os funcionários que fazem parte dela (KROETZ, 2000; TINOCO, 2001).

O Balanço Social - tratado neste trabalho como sinônimo dos termos "Demonstração Social", "Relatório Social" e "Relatório de Sustentabilidade", visto que incorporam os aspectos econômico, social e ambiental do desempenho 
da organização - é um produto da Contabilidade que auxilia as organizações a tornar mais transparente sua forma de atuação. Sua publicação contribui para que "a sociedade como um todo conheça melhor a empresa” (MARTINS, 1997).

A Demonstração de Valor Adicional (DVA) é parte do Balanço Social e componente importantíssimo desse balanço, deve ser entendida como uma forma de Contabilidade auxiliar a medir e demonstrar a capacidade da empresa para gerar e distribuir riqueza (SANTOS apud Ribeiro, 2005). Esse demonstrativo é uma forma de evidenciar a função social da empresa e sua contribuição para formar riqueza global do País, o PIB, ao contrário da DRE, cuja ênfase recai sobre a última linha e cujo interesse majoritário é dos acionistas (MARTINS, 1997).

A divulgação do Balanço Social não é obrigatória em todos os países. $\mathrm{O}$ primeiro país que regulamentou a sua publicação foi a França, por meio da Lei n. 77.769, de 12 de julho de 1977, sendo este exemplo seguido por Portugal, em 1985, e posteriormente pela Bélgica, em 1996 (TINOCO, 2001). No Brasil, não existe a obrigatoriedade de elaboração e publicação do Balanço Social, porém, por parte de alguns setores do governo e da sociedade civil, existe a intenção de que isso ocorra (SILVA e FREIRE, 2001).

\subsection{Ativo, Passivo e Patrimônio Líquido Ambiental}

O Ativo Ambiental é constituído pelo conjunto de bens adquiridos pela organização com o intuito de controlar, preservar e recuperar o meio ambiente. Esses Ativos são decorrentes de investimentos na área do meio ambiente e deverão ser classificados em títulos contábeis específicos, identificando, de forma adequada, os estoques ambientais, o ativo permanente imobilizado ambiental e o diferido ambiental (ALBUQUERQUE et al., 2007).

O termo "Passivo Ambiental" causa muitas discussões por estar frequentemente ligado a multas, penalidades ou violações a leis ambientais. É muito comum a associação entre custos e o cumprimento de regulamentações. Apesar de ser um termo abrangente, pode-se definir Passivo Ambiental como uma obrigação adquirida em decorrência de transações anteriores ou presentes, que provocaram ou provocam danos ao meio ambiente, de forma voluntária ou involuntária, os quais deverão ser indenizados pela entrega de benefícios econômicos ou prestação de serviços em um momento futuro (RIBEIRO, 2000; GALDINO et al., 2002).

Por fim, Albuquerque et al. (2007) dizem que o Patrimônio Líquido Ambiental, por sua vez, é constituído pelo capital acumulado dos proprietários do empreendimento, sendo representado pelo conjunto dos ativos e passivos ambientais. O patrimônio ambiental, embora existente, não é passível de segregação dos elementos que compõem o patrimônio líquido na sua forma tradicional e assim Ribeiro e Gratão (2000) conclui que não há que se pensar na identificação física do 
patrimônio ambiental, porque, já que os recursos próprios são formados ao longo da existência da companhia e são utilizados indistintamente nas mais variadas necessidades apresentadas pelo processo operacional da empresa, não cabe, portanto, a identificação do capital ambiental ou das reservas de lucros ambientais, exceto a de contingências ambientais.

\subsection{Custos Ambientais}

De acordo com Ribeiro (2005), custos ambientais são todos os gastos envolvidos com o gerenciamento ambiental, consumidos no período e incorridos na área administrativa. Qualquer empresa necessita dos serviços de um departamento que desenvolva atividades inerentes à proteção do meio ambiente. Esses gastos devem ser contabilizados como despesas do exercício em curso; embora possam ter benefícios futuros, dificilmente estes podem ser mensurados com clareza.

Em relação aos muitos gastos na área ambiental e social, a mesma Ribeiro (2005) continua afirmando que alguns contabilistas defendem que os custos sociais devem ser incorporados aos produtos por meio do custo padrão, orçamentos e provisões, ela afirma que se pode compreender custos ambientais todos aqueles relacionados, direta ou indiretamente, com a proteção do meio ambiente. Para a ONU (apud Ribeiro, 2005), os custos ambientais compreendem os gastos realizados para gerenciar os impactos das atividades das empresas nesse setor de forma ambientalmente responsável, além de outros gastos com o mesmo objetivo.

\subsection{Goodwill}

Para Schmidt e Santos (2003), o “Goodwill é considerado o mais intangível dos intangíveis, é definido como sendo qualquer excesso de valor pago em uma aquisição, em relação à participação do adquirente no valor justo dos ativos e passivos identificáveis da entidade adquirida". Martins (1972, p. 55) afirma que

O Goodwill tem sido motivo de estudos, debates, artigos, livros, legislação, concordâncias e divergências desde há muito anos. As citações e referências a ele datam de séculos atrás, mas a primeira condensação do seu significado e o primeiro trabalho sistemático tendo-o como tema central parecem ter existido em 1891.

Ao tratarem da mensuração do Goodwill, Hendriksen e Van Breda (1999, p. 392) consideram que Goodwill é o mais importante ativo intangível na maioria das empresas. Frequentemente, é o ativo de tratamento mais complexo porque carece de muitas das características associadas a ativos, tais como identificabilidade e separabilidade. Em consequência, sua mensuração tem recebido atenção especial 


\subsection{Sistema de Gestão Ambiental e Auditoria Ambiental}

Um marco na normalização ambiental foi a criação da norma britânica BS 7750, publicada em 1992. Com base nela, diversas normas foram elaboradas em outros países. No âmbito da International Standardization Organization ISO, foi criado um grupo de assessoria para estudar as questões decorrentes da proliferação de normas ambientais e seus impactos sobre o comércio internacional. Esse grupo recomendou a criação de um comitê específico para a elaboração de normas sobre gestão ambiental. A norma ISO 14001 foi publicada em setembro de 1996, compreendendo especificações normativas acordadas internacionalmente e estabelecendo critérios de gestão ambiental compatíveis com um sistema de gerenciamento voltado à viabilidade da produção ecologicamente correta e à indução de uma cultura participativa baseada na aprendizagem organizacional, na disseminação de valores ambientais e na sustentabilidade dos recursos naturais (MAIMON, 1999; VALLE, 1996; D’AVIGNON, 1996; SCHERER, 1998).

Para Donaire (1999, p.108), os programas de gestão ambiental "estabelecem atividades a serem desenvolvidas, a seqüência entre elas, bem como quem são os responsáveis pela sua execução". A partir dessa acepção, pode-se inferir que a gestão ambiental tem se apresentado como uma das mais importantes atividades relacionadas com qualquer empreendimento. Valle (1996) conclui que a gestão ambiental é como um conjunto de ações e procedimentos bem delineados e adequadamente aplicados que visam à redução e ao controle dos impactos gerados por um empreendimento no meio ambiente.

No que tange às vantagens da empresa, Maimon (1996, p.72) afirma que "em termos organizacionais, os parâmetros relacionados ao meio ambiente passam a ser levados em conta no planejamento estratégico, no processo produtivo, na distribuição e disposição final do produto." O mesmo autor descreve as cinco etapas sucessivas e contínuas para a implementação do Sistema de Gestão Ambiental, que são: Política Ambiental da Organização; Planejamento; Implementação e Operação; Monitoramento e Ações Corretivas; e Revisões no Gerenciamento. O Sistema de Gestão Ambiental - SGA pode ser aplicado em qualquer tipo de empresa que queira adotar uma política ambiental. A empresa que adotar um sistema desses pode contar com meios de melhor apropriação de custos e alocação de recursos disponíveis, além de adicionar valor visando à vantagem competitiva mediante o seu público alvo que opta por produtos ambientalmente saudáveis (ALBUQUERQUE et al., 2007).

Tratando-se da auditoria ambiental, Donaire (1995, p. 109) afirma que "a auditoria ambiental é um fator importante para uma efetiva política de minimização dos impactos ambientais das empresas e de redução de seus índices de poluição". 
Com isso, tem-se o reforço de que a auditoria ambiental deve estruturar seus trabalhos com foco na gestão de maneira a proporcionar a eficácia e a eficiência do processo decisório. A auditoria ambiental é orientada por três documentos: ISO 14.010, 14.011 e 14.012. Albuquerque et al. (2007) afirmam que, conforme a seção 5 da ISO 14.010, "Diretrizes para Auditoria Ambiental - princípios gerais", os sete elementos principais na condução das auditorias ambientais são: 1. Objetivos e escopo; 2. Objetividade, independência e competência; 3. Profissionalismo; 4. Procedimentos sistemáticos; 5. Critérios, evidências e constatações de auditoria; 6. Confiabilidade das constatações e conclusões de auditoria; 7. Relatório de auditoria.

\subsection{Legislação}

No que cabe a legislações pertinentes à área ambiental, uma das mais relacionadas foi sancionada em 1998, a Lei Federal n. 9.605, que trata especificamente de sanções penais e administrativas para casos de condutas e atividades lesivas ao meio ambiente, conhecida como Lei de Crimes Ambientais. Sua inovação está em punir a pessoa física responsável pelas ações das empresas, isto é, o executante da infração, além da pessoa jurídica em si.A lei estabelece rígidas penalidades para seus infratores, o que pode causar sérios impactos na situação patrimonial da empresa (RIBEIRO, 2005).

\section{Análise dos Dados da Pesquisa de Campo}

\subsection{Perfil dos Respondentes}

Na primeira parte do questionário, pode-se verificar que o grupo de respondentes à pesquisa de campo deste trabalho consiste de $74 \%$ de contadores, $5 \%$ de administradores, $3 \%$ de economistas, 5\% de matemáticos, $8 \%$ de biólogos e $5 \%$ outros cursos como História e Física.

No questionário não foram feitas perguntas sobre distinção de sexo, por não se julgar relevante para se alcançar o objetivo do estudo. Com relação à instituição onde foi realizado o curso de Graduação, 14\% cursaram em faculdades públicas, e $86 \%$, em particulares. Em se detendo ao grupo dos contadores, esses dados se repetem.

\subsection{Análise e Discussão dos Dados}

Como já foi exposto anteriormente, a análise detalhada dos dados alcançados, por meio da pesquisa de campo, será focada no grupo dos contadores, grupo 
de interesse da pesquisa.

O Quadro 1 mostra que, dos 58 contadores, $83 \%$ disseram nunca terem cursado nenhuma disciplina de Contabilidade Ambiental ou correlata. Após uma análise mais detalhada, foi percebido que $20 \%$ dos entrevistados de faculdades privadas cursaram alguma disciplina ou correlata na área de Contabilidade Ambiental, enquanto nenhum dos entrevistados que tiveram sua formação em instituições públicas cursaram nenhum tipo dessas disciplinas. Verificou-se também, mesmo não sendo o objeto de estudo, que as instituições de ensino públicas até o período letivo de 2007.2 não ofereciam disciplinas nem correlatas na área de Contabilidade Ambiental.

\section{Quadro 1: Questão n.1}

\begin{tabular}{|l|l|l|}
\hline PERGUNTA & \multicolumn{2}{|l|}{ RESPOSTAS } \\
\hline Já cursou alguma disciplina de Contabilidade Ambiental ou correlata? & Sim & Não \\
& $17 \%$ & $83 \%$ \\
\hline
\end{tabular}

Fonte: Dados da pesquisa.

Diante da pergunta sobre a frequência de participação em eventos, como palestras, seminários e congressos na área de Contabilidade Ambiental, conforme o Quadro 2, apenas $12 \%$ já haviam participado de algum evento da área.

Quadro 2: Questão n.2

\begin{tabular}{|l|l|l|}
\hline PERGUNTA & \multicolumn{2}{|l|}{ RESPOSTAS } \\
\hline Já participou de alguma palestra, congresso ou seminário sobre Contabilidade & Sim & Não \\
Ambiental? & $12 \%$ & $88 \%$ \\
\hline
\end{tabular}

Fonte: Dados da pesquisa.

No questionamento relacionado ao contato do contador com materiais de leitura, científico e profissional sobre o assunto, $48 \%$ disseram que nunca tiveram contato com nenhum tipo de material impresso (livros, revistas, etc.) da área de Contabilidade Ambiental, conforme Quadro 3:

\section{Quadro 3: Questão n.3}

\begin{tabular}{|l|l|l|}
\hline PERGUNTA & \multicolumn{2}{|l|}{ RESPOSTAS } \\
\hline Já teve contato com algum material impresso (livro, revista, etc.) na área de Contabilidade & Sim & $\begin{array}{l}\text { Não } \\
\text { Ambiental? }\end{array}$ \\
\hline
\end{tabular}

Fonte: Dados da pesquisa.

Aos que tiveram contato com algum tipo de material da área de Contabilidade Ambiental, 67\% disseram que a qualidade do material que existe à disposição não é clara e objetiva, 14\% disseram que eram de boa qualidade e 19 $\%$ não souberam, conforme Quadro 4. 
Quadro 4: Questão n.4

\begin{tabular}{|c|c|c|c|}
\hline PERGUNTA & \multicolumn{3}{|c|}{ RESPOSTAS } \\
\hline $\begin{array}{l}\text { Em sua opinião, a literatura existente sobre Contabilidade Ambiental } \\
\text { aborda o assunto de forma objetiva e clara? }\end{array}$ & $\begin{array}{l}\text { Sim } \\
14 \%\end{array}$ & $\begin{array}{l}\text { Não } \\
67 \%\end{array}$ & $\begin{array}{lll}\text { Não } & \text { sei informar } \\
19 \% & & \end{array}$ \\
\hline
\end{tabular}

Fonte: Dados da pesquisa.

$\mathrm{O}$ alto percentual de contadores que desconhecem as particularidades da Contabilidade Ambiental é demonstrada explicitamente na resposta da pergunta onde foi pedido para o entrevistado fazer uma autoavaliação sobre seu grau de conhecimento das peculiaridades desta Contabilidade, onde $38 \%$ disseram desconhecer totalmente, $47 \%$ disseram conhecer um pouco, $15 \%$ conhecem razoavelmente e ninguém disse que conhecia muito ou totalmente.

Na última pergunta do questionário, direcionada ao perfil dos contadores, foi feito um questionamento acerca da atuação profissional na área de Contabilidade Ambiental: 100\% da amostra pesquisada nunca exerceu qualquer atividade relacionada a Contabilidade Ambiental.

As cinco primeiras questões apontam que apenas 10 dos entrevistados têm uma percepção razoável sobre Contabilidade Ambiental, e apenas 8 já tiveram algum tipo de contato materiais da área. Se o questionário terminasse nesse ponto, a pesquisa já demonstraria o pequeno grau de interesse e contato dos contadores com assuntos pertinentes à Contabilidade Ambiental. Entretanto, ainda será analisado o resultado da segunda parte do questionário onde foram feitas 10 perguntas sobre peculiaridades Contabilidade Ambiental e assuntos relacionados à área, visando medir o seu grau de conhecimento, por parte dos contadores.

Na primeira pergunta, foi pedido que o entrevistado respondesse sobre a obrigatoriedade das Demonstrações Contábeis de acordo com a Lei n. 6.404/76 como podemos ver na Tabela 1 logo abaixo:

Tabela 1: Conhecimento sobre Obrigatoriedade das Demonstrações Contábeis de acordo com a Lei n. 6.404/76

\begin{tabular}{llll}
\hline Demonstrações Contábeis & Correta & Errado & Não soube Informar \\
\hline Obrigatoriedade do Balanço Patrimonial & $91 \%$ & $2 \%$ & $7 \%$ \\
Obrigatoriedade da D.R.E. & $89 \%$ & $2 \%$ & $9 \%$ \\
Obrigatoriedade Da D.M.PL & $76 \%$ & $15 \%$ & $9 \%$ \\
Obrigatoriedade do Balanço Social & $72 \%$ & $12 \%$ & $16 \%$ \\
Obrigatoriedade D.V.A. & $74 \%$ & $4 \%$ & $22 \%$ \\
\hline
\end{tabular}

Fonte: Dados da pesquisa.

Pode-se verificar que os demonstrativos onde houve maior porcentagem de entrevistados que não souberam responder foram os de cunho Social e Ambiental.

Ainda com relação à Tabela 1 , quando foi analisado o quantitativo total 
de acertos e erros, verificou-se que $80 \%$ dos entrevistados souberam responder sobre a obrigatoriedade das Demonstrações Contábeis, 9\% responderam errado e $11 \%$ não souberam dar a informação

Na questão 2 da segunda parte do questionário, conforme o Quadro 5, trata-se da Despesa Ambiental, peculiaridade bastante discutido na Contabilidade Ambiental, e cerca de 46\% acertaram a resposta, 5\% erraram e 49\% não souberam informar.

\section{Quadro 5: Despesa Ambiental}

\begin{tabular}{|c|c|c|c|}
\hline PERGUNTA & \multicolumn{3}{|c|}{ RESPOSTAS } \\
\hline $\begin{array}{l}\text { Gastos realizados para gerenciar os impactos das atividades da empresa nesse } \\
\text { setor, de forma ambientalmente saudável, é classificada como DESPESA } \\
\text { AMBIENTAL? }\end{array}$ & $\begin{array}{l}\text { Acertou } \\
46 \%\end{array}$ & $\begin{array}{l}\text { Errou } \\
5 \%\end{array}$ & $\begin{array}{l}\text { Não Informou } \\
49 \%\end{array}$ \\
\hline
\end{tabular}

Fonte: Dados da pesquisa.

Na terceira questão apresentada no Quadro 6, a seguir, apenas 23\% dos entrevistados demonstraram conhecimento sobre Sistema de Gestão Ambiental (SGA), mecanismo dos gestores cujas intenções são ambientalmente responsáveis. Numa maioria expressiva, $77 \%$ não souberam responder quais são as etapas para a implementação de um SGA.

\section{Quadro 6: Gestão Ambiental}

\begin{tabular}{|l|l|l|l|}
\hline PERGUNTA & \multicolumn{1}{l|}{ RESPOSTAS } \\
\hline Existem 5 etapas sucessivas para implementação do SISTEMA DE GESTÃO & Acertou & Errou & Não \\
AMBIENTA: Política Ambiental da Organização; Planejamento; Implementação e & $21 \%$ & $2 \%$ & $\begin{array}{l}\text { Informou } \\
77 \%\end{array}$ \\
Operação; Monitoramento e Ações Corretivas; e Revisão do Gerenciamento. & & & \\
\hline
\end{tabular}

Fonte: Dados da pesquisa.

A quarta questão trata sobre os documentos regulatórios da Auditoria Ambiental, representado pelo Quadro 7 e evidencia que uma quantidade significativa (cerca de $80 \%$ ) de respondentes não sabia responde à pergunta. Dos poucos que se propuseram a responder, $16 \%$ acertaram.

\section{Quadro 7: Auditoria Ambiental}

\begin{tabular}{|l|l|l|l|}
\hline PERGUNTA & \multicolumn{3}{|l|}{ RESPOSTAS } \\
\hline AUDITORIA AMBIENTAL é orientada por documentos: ISSO 14.010,14.011, & $\begin{array}{l}\text { Acertou } \\
16 \%\end{array}$ & $\begin{array}{l}\text { Errou } \\
3 \%\end{array}$ & $\begin{array}{l}\text { Não Informou } \\
14.012 .\end{array}$ \\
\hline
\end{tabular}

Fonte: Dados da pesquisa.

Na quinta questão onde indagava ao entrevistado sobre seu conhecimento acerca da legislação pertinente a fatos ambientais, a Lei Federal n. 9.605, o pequeno quantitativo de respondestes persistiu, e apenas $16 \%$ dos entrevistados responderam, porém todos os que se dispuseram a responder acertaram a pergunta. 
Quadro 8: Legislação

\begin{tabular}{|l|l|l|l|}
\hline PERGUNTA & \multicolumn{1}{l|}{ RESPOSTAS } \\
\hline Em 1998 foi sancionada a Lei Federal n. 9.605, conhecida como Lei de Crimes & $\begin{array}{l}\text { Acertou } \\
16 \%\end{array}$ & $\begin{array}{l}\text { Errou } \\
0 \%\end{array}$ & $\begin{array}{l}\text { Não Informou } \\
84 \%\end{array}$ \\
\hline Ambientais & &
\end{tabular}

Fonte: Dados da pesquisa.

Na sexta pergunta, que trata da definição de Goodwill, mais uma vez a falta de informação perdurou com $64 \%$, dos respondentes, e $21 \%$ acertaram a resposta, superando os erros. Conforme Quadro 9 a seguir:

\section{Quadro 9: Goodwill}

\begin{tabular}{|l|l|l|l|}
\hline PERGUNTA & \multicolumn{2}{|l|}{ RESPOSTAS } & Não informou \\
\hline $\begin{array}{l}\text { A diferença entre o valor atual da empresa como um todo,em termos de } \\
\text { capacidade de geração de lucros futuros ,e o valor econômico dos seus ativos }\end{array}$ & $\begin{array}{l}\text { Acertou } \\
\text {,essa é a definição de GOODWILL. }\end{array}$ & $15 \%$ & $64 \%$ \\
\end{tabular}

Fonte: Dados da pesquisa.

Na sétima questão, foi levantado um questionamento sobre a definição e diretrizes do ISO 14.000, de grande importância no âmbito empresarial com perspectivas de atitudes ambientalmente saudáveis, tipo de informação que não se detém a estudiosos da área. Mais uma vez, o número de respondentes que não souberam (74\%) responder se a afirmativa está correta ou não foi bem superior aos que tentaram (26\%) responder, como mostra logo abaixo o Quadro10.

Quadro 10: ISO 14.000

\begin{tabular}{|l|l|l|l|}
\hline \multicolumn{2}{|c|}{ PERGUNTA } & \multicolumn{1}{|l|}{ RESPOSTAS } \\
\hline $\begin{array}{l}\text { O ISO 14.000, estabelece as diretrizes básicas para a implementação de sistema de gestão } \\
\text { ambiental, o qual constitui um processo estruturado, genérico e completo, que visa à } \\
\text { melhoria do desempenho nas empresas e globalmente. }\end{array}$ & $22 \%$ & $\begin{array}{l}\text { Errou } \\
4 \%\end{array}$ & $74 \%$ \\
\hline
\end{tabular}

Fonte: Dados da pesquisa.

Na oitava questão, é medido o conhecimento do entrevistado sobre Custos Ambientais, se o contador sabe distinguir os gastos ambientais, e, não diferentemente do resto da pesquisa, mais de $60 \%$ não souberam dar a resposta, mas, diferente dos demais questionamentos, o número de erros e acertos foi muito próximo, como se pode perceber no Quadro 11.

\section{Quadro 11: Custos Ambientais}

\begin{tabular}{|l|l|l|}
\hline \multicolumn{2}{|c|}{ PERGUNTA } & \multicolumn{2}{|l|}{ RESPOSTAS } \\
\hline $\begin{array}{l}\text { A restauração, descontaminação, tratamento de emissões e depreciação de equipamentos } \\
\text { são classificados como CUSTOS AMBIENTAIS. }\end{array}$ & $\begin{array}{l}\text { Acertou } \\
18 \%\end{array}$ & $\begin{array}{l}\text { Errou } \\
19 \%\end{array}$ \\
\hline
\end{tabular}

Fonte: Dados da pesquisa. 
Na nona questão, é visto se o entrevistado sabe informar quais contas fazem parte de um Ativo Ambiental, com mais de 70\%, o alto percentual de entrevistados que não souberam responder à pergunta persiste, e só 5\% dos respondentes acertaram a pergunta como se pode ver no Quadro 12.

Quadro 12: Ativo Ambiental

\begin{tabular}{|l|l|l|l|}
\hline \multicolumn{2}{|c|}{ PERGUNTA } & \multicolumn{2}{|l|}{ RESPOSTAS } \\
\hline $\begin{array}{l}\text { Estoques, Imobilizados, Diferidos, Provisão para desvalorização, Depreciação Acelerada e } \\
\text { Goodwill, fazem parte do ATIVO AMBIENTAL. }\end{array}$ & $\begin{array}{l}\text { Acertou } \\
5 \%\end{array}$ & $\begin{array}{l}\text { Errou } \\
21 \%\end{array}$ & $\begin{array}{l}\text { Não informou } \\
74 \%\end{array}$ \\
\hline
\end{tabular}

Fonte: Dados da pesquisa.

Na décima e última pergunta, é feito um questionamento sobre as demonstrações contábeis relacionadas ao meio social e ambiental como Balanço Social e Demonstrativo de Valor Adicional. Ao contrário dos outros questionamentos, mais de $60 \%$ se propuseram a responder à pergunta, e, diferentemente das outras questões, a maioria, com $46 \%$ dos respondentes, acertou o questionamento, como é observado no Quadro 13.

Quadro 13: Balanço Social

\begin{tabular}{|l|l|l|l|}
\hline \multicolumn{2}{|c|}{ PERGUNTA } & RESPOSTAS & Acertou \\
\hline O DEMONSTRATIVO DE VALOR ADICIONAL faz parte do Balanço Social. & $46 \%$ & Errou & Informou \\
& & $33 \%$ & \\
\hline
\end{tabular}

Fonte: Dados da pesquisa.

Quando analisado o quantitativo total de erros e acertos entre todas as perguntas feitas, chega-se a um número muito expressivo e alarmante, que corrobora com o que foi presente durante toda a pesquisa: $65 \%$ das respostas apontaram que os entrevistados não sabiam responder à pergunta, apenas $25 \%$ responderam corretamente e, por fim, 10\% das respostas estavam erradas.

\section{Considerações Finais}

A Contabilidade Ambiental surge com o objetivo de auferir os resultados das atividades de empresas que se relacionam com o meio ambiente, por meio de uma estratégia que venha encontrar o melhor caminho para o desenvolvimento sustentável.

Após análise das informações levantadas pela pesquisa bibliográfica, pôde-se observar que a Contabilidade Ambiental tem peculiaridades que diferem da Contabilidade de outras áreas, dentre eles as formas pelas quais as demonstrações contábeis são abordadas, o balanço social como instrumento informacional, as diferentes abordagens de ativo, passivo e Patrimônio Líquido, entre outros conceitos desenvolvidos. 
Estes conceitos foram utilizados como respaldo teórico para a construção do instrumento de coleta de dados da pesquisa, que teve como intuito responder a pergunta de pesquisa. Sendo assim, este estudo teve por objetivo identificar qual o grau de conhecimento dos contadores a cerca das peculiaridades da Contabilidade Ambiental.

Inicialmente, foi solicitado o entrevistado se auto-avaliasse sobre seu conhecimento em contabilidade ambiental, 37\% dos respondentes afirmaram desconhecer totalmente a temática, apenas $15 \%$ disseram conhecer razoavelmente e ninguém disse conhecer muito ou totalmente a temática. De maneira expressiva, $40 \%$ nunca ouviram falar das peculiaridades da Contabilidade Ambiental e $100 \%$ afirmaram nunca ter exercido qualquer atividade relacionada esta área em específico.

Mais adiante, $90 \%$ da amostra nunca participou de nenhum evento referente a Contabilidade Ambiental, e em torno da metade da amostra nunca teve nenhum contanto com materiais de leitura sobre o tema. Do total dos respondentes que afirmaram ter contato com materiais de estudos, $70 \%$ disseram que estes materiais não são claros e objetivos.

Ao serem abordados sobre as peculiaridades da Contabilidade Ambiental, como Custos Ambientais e Despesas Ambientais, cerca de 50\% da amostra não souberam responder as assertivas, quando questionados sobre Sistemas de Gestão Ambiental, Gestão Ambiental e Auditoria Ambiental, em toro de 80\% não souberam responder as perguntas. Quando questionados sobre Custos Ambientais, Despesas Ambientais e Ativo Ambiental , 70\% não souberam responder as questões. Apenas na questão sobre Demonstrativo de Valor Adicionado que houve um acerto de aproximadamente de 50\%. Ao final, quando analisados o total de erros quantitativamente entre todas as perguntas, identificou-se que cerca de $65 \%$ das respostas apontaram que os entrevistados não sabiam responder as perguntas.

Sendo assim, pode-se concluir que a cerca dessas peculiaridades os Contadores pesquisados não têm um conhecimento adequado, ou melhor, o mínimo de informações que se deve ter sobre o tema.

Um dos agravantes deste cenário é a falta de interesse dos profissionais em ler artigos científicos, matérias jornalísticas e livros na área, sendo atenuada pela ausência em participação em eventos relacionados à Contabilidade Ambiental.

Diante destes achados é necessário fazer-se uma reflexão a cerca destes resultados, pois os discentes de hoje são os futuros profissionais; e os mesmo precisam estar preparados para exercer a profissão, pois a Contabilidade Ambiental está em ascensão, e a demanda por profissionais qualificados no mercado é crescente, principalmente diante atual discussão sobre desenvolvimento sustentável.

Este estudo teve como principal limitação o fato da amostra restringir-se apenas a uma instituição pública de ensino do estado de Pernambuco, e ao ques- 
tionário ter sito aplicado apenas em cursos de Pós-Graduação (lato sensu).

Sendo assim, sugere-se para futuros estudos, ampliar-se o número de respondentes da pesquisa e utilizar-se da metodologia deste trabalho em outras instituições de ensino, em outras regiões do país, para que se possam detectar as possíveis diferenças regionais no grau de conhecimento dos profissionais de contabilidade

\section{Referências}

BEUREN, I. M.; RAUPP, F. M. Metodologia de pesquisa aplicada às ciências sociais. BEUREN, I. M. (Org.). Como elaborar trabalhos Monográficos em Contabilidade. São Paulo: Atlas, 2004. p. 76-97.

COOPER, D. R.; SCHINDLER, P. S. Métodos de Pesquisa em administração. 7. ed. Bookman: Porto Alegre, 2003.

COSTA, M de S; LIBONATI, J. J.; RODRIGUES, R. N. Conhecimentos sobre Marticuliaridades da Contabilidade Rural:Um Estudo Exploratório com Contadores da Região Metropolitana do Recife.Contexto, Porto Alegre, .4, n. 7, $2^{\circ}$ semestre, 2004.

D’AVIGNON, A. Normas Ambientais ISO 14000 - Como podem Influenciar sua Empresa. Rio de Janeiro: CNI, 1996.

DENZIN, N. K.; LINCOLN, Y. S. Handbook of qualitative research. London: Sage, 1994.

FERREIRA, A. C. de S. Contabilidade Ambiental. São Paulo: Atlas, 2003.

. Uma contribuição para a gestão econômica do meio ambiente - um enfoque sistêmico da informação. 1998. Tese de Doutorado. Faculdade de Economia, Administração e Contabilidade. Universidade de São Paulo, São Paulo.

FRANCO, H. A Contabilidade na Era da Globalização: Temas Discutidos no XV Congresso Mundial de Contadores, Paris, de 26 a 29/10/1997. São Paulo: Atlas, 1999.

FREY, M. R.; PIRES JÚNIOR, R. B. Evidenciação das Informações Ambientais nas Demonstrações Contábeis, In: Anais II Seminário de Trabalhos Científicos em Contabilidade da UNISC - 17 e 18/09/2001. Porto Alegre: Conselho Regional de Contabilidade, 2001. p. 115 - 129. 
GALDINO, C. A. B. et al. Passivo ambiental das organizações: uma abordagem teórica sobre avaliação de custos e danos ambientais no setor de exploração de petróleo.In: XXII ENEGEP - Curitiba, Paraná de 22 a 25 de outubro de 2002.

GEORGE H. B. Exploratory research remains essential for industry Research Technology Management. Washington: Nov/Dec 2002. Vol. 45, Iss. 6; p. 26.5 pages.

HENDRIKSEN, Eldon S.; VAN BREDA, Michael F. Teoria da Contabilidade. Tradução por Antonio Zoratto Sanvicente. 5. ed. São Paulo: Atlas, 1999.

MAIMON, D. ISO 14001 - Passo a Passo da Implantação nas Pequenas e Médias Empresas. Rio de Janeiro: Qualitymark Editora Ltda., 1999.

MALHOTRA, N. K. Pesquisa de Marketing: Uma Orientação Aplicada. 3. ed. Porto Alegre: Bookman, 2001.

MARION, J. C. Contabilidade Empresarial. 11. ed. São Paulo: Atlas, 2005.

MARTINS. E. Balanço Social: idéia que merece permanecer. Gazeta Mercantil. São Paulo, p. A3,18 set.1997.

MARTINS, G. A.; THEÓPHILO, C. R. Metodologia da Investigação Científica para Ciências Sociais Aplicadas. São Paulo: Editora Atlas, 2007. v. 1

QUEIROZ, R. L. S.; QUEIROZ, E. S. A Contabilidade como um Instrumento de Gestão Ambiental Empresarial, e sua Contribuição a Melhoria da Qualidade de Vida Planetária. Revista Pensar Contábil - CRC/RJ. Rio de Janeiro, ano 3. n. 9, p.78-83, ago./out. 2000.

RIBEIRO, M. de S. Custeio das Atividades de Natureza Ambiental. 1998. Tese de Doutorado. Faculdade de Economia, Administração e Contabilidade. Universidade de São Paulo, São Paulo.

RIBEIRO, M.de S.; GRATÃO, A.D.Custos Ambientais - o caso das empresas distribuidoras de combustíveis. In: VII Congresso Brasileiro de Custos, RecifePE - 28/07 a 04/08/2000.

RIBEIRO, M. S; LISBOA, L. P. Passivo Ambiental. In: XVI Congresso Brasileiro de Contabilidade, Goiânia - GO, 2000.

RUIZ, J. Á. Metodologia cientifica: guia para eficiência nos estudos. 2. ed. São Paulo: Atlas, 1988. 
SCHMIDT, P; SANTOS, J. dos S. Ativos Intangíveis nas Normas Internacionais - Iasb. In: IX Convenção de Contabilidade do Rio Grande do Sul, 2003. Anais eletrônicos... Disponível em: http://ccontabeis.com.br/conv/t01.pdf

SCHERER, R. L. Sistema de Gestão Ambiental: Ecofênix, um Modelo de Implementação e Aprendizagem. Florianópolis, 1998. Exame de Qualificação de Doutorado em Engenharia de Produção - Universidade Federal de Santa Catarina.

SILVA, A. C. R. da. Metodologia da pesquisa aplicada à Contabilidade. 1. ed. São Paulo: Atlas, 2003.

TRIVIÑOS, A. N. S. Introdução à pesquisa em ciências sociais: a pesquisa qualitativa em educação. São Paulo: Atlas, 1987.

VALLE, C. E. Como se Preparar Para as Normas ISO 14000 - Qualidade Ambiental - O Desafio de Ser Competitivo Protegendo o Meio Ambiente. São Paulo: Pioneira Administração e Negócios \& ABIMAQ/SINDIMAQ, 1996. 
